\title{
How valence affects language processing: Negativity bias and mood congruence in narrative comprehension
}

\author{
GiovanNa EGIDI \\ University of Chicago, Chicago, Illinois \\ AND \\ RICHARD J. GERRIG \\ Stony Brook University, Stony Brook, New York
}

\begin{abstract}
The present research examined how positive and negative moods affect readers' understanding of positive and negative story endings. It demonstrated how negativity bias and mood congruence emerge during narrative comprehension. Participants were induced to experience either a positive or a negative mood and then read stories that could have either a positive or a negative ending. In Experiment 1, participants took longer to integrate negative endings than positive endings, independent of their mood. In Experiment 2, participants judged as more surprising those endings that did not match their mood. The present results illustrate that ending valence has strong influence on moment-by-moment reading, but that readers' moods influence expectations for story outcomes once readers reflect on a complete representation of the story.
\end{abstract}

Imagine reading a story about two friends: They are rushing to a computer store to get a deal before the store closes. As you read, you know that the story permits one of two outcomes: Either they get their deal or they do not. Will you attend differently to the ending as a function of its positive or negative valence? Now suppose that this anecdote about the two friends occurs in the context of a novel. What you read in the earlier chapters may very well have induced you to be in a happy or a sad mood. Will the valence of your present mood-positive or negative - affect the way in which you process the outcome of the friends' sprint to the computer store? Will your mood influence your reading even though it was induced by content completely unrelated to the two friends' anecdote?

In the present article, we present two studies that explored whether the positive and negative content of story endings and readers' moods affect how people comprehend the stories they read. In particular, we focus on how the valence of story outcomes and readers' moods - either of which can be positive or negative - interact when readers process and reflect on happy and unhappy endings.

Consider the valence of story outcomes. Narratives permit both positive and negative endings: Teams win or lose; villains get captured or remain free. To date, theories of text processing have not focused on how the valence of story endings affects the processing of narratives. However, research suggests that this is a topic of much potential importance. In fact, positive and negative forms of information are known to be processed differently. In particular, researchers have documented a strong negativity bias, or a heightened sensitivity to negative information, at different levels of cognitive processing (for a review, see Baumeister, Bratslavsky, Finkenauer, \& Vohs, 2001; Rozin \& Royzman, 2001). For instance, negative attributes exert greater influence on judgments and persuasion (Herr, Kardes, \& Kim, 1991); negative traits have greater influence on forming an impression of another person (Peeters \& Czapinski, 1990); and negative information has a greater impact on evaluative categorizations than does positive information (Cacioppo, Gardner, \& Berntson, 1997; Ito, Larsen, Smith, \& Cacioppo, 1998). These effects often rely on the fact that negative information has a strong attention-capturing quality: Negative stimuli are detected faster (Dijksterhuis \& Aarts, 2003), draw more attention (Pratto \& John, 1991; Smith, Cacioppo, Larsen, \& Chartrand, 2003), and are more difficult to divert attention from (McKenna \& Sharma, 1995; Pratto \& John, 1991). Thus, the research literature leads to the strong prediction that negative outcomes (as compared with positive outcomes) will command more attention in moment-bymoment comprehension.

Mood, however, may counteract or modulate this negativity bias. Prior research has demonstrated that mood affects how people process information. In particular, people process information more carefully when it is consistent with their mood. This often results in both facilitated recall of mood-congruent information and formula-

G. Egidi, g.egidi@gmail.com 
tion of mood-congruent judgments and evaluations (for a review, see L. L. Martin \& Clore, 2001). For this reason, we might expect, for example, that positive information would have a greater influence on comprehension than would negative information when a reader is experiencing a positive mood.

The influence of mood on judgments and on information processing depends crucially on the requirements of the process. The more extensively people have to process information to compute a response, the more likely it is that mood will influence the process (Bower \& Forgas, 2000; Forgas, 1995; Watkins, Mathews, Williamson, \& Fuller, 1992). For example, mood does not affect the retrieval of already-formed judgments (Fiedler, 1991; Forgas, 1995), but it affects the formation of novel judgments and impressions (Forgas, 1992; Forgas \& Bower, 1987). Mood does not affect perceptual implicit memory tasks, such as the identification of a word presented for only a few milliseconds and then masked. However, it affects conceptual implicit memory tasks in which the level of elaboration of the stimulus is greater, such as forming word associations and finding words that fit a definition (Watkins, 2002; Watkins, Martin, \& Stern, 2000). Mood also affects explicit memory tasks that involve even greater levels of stimulus elaboration, such as the recall of word lists, personal experiences, or events from a narrative (Bower, 1981; Bower, Gilligan, \& Monteiro, 1981).

Research prompted by the affect infusion model (Forgas, 1995) has argued that the effect of mood on social judgments varies along a processing continuum, which has its strongest influence on substantive processing. This type of processing underlies the formulation of novel judgments for which people have to "select, learn, and interpret novel information about a target and to relate this information to preexisting knowledge structures" (Forgas, 1995, p. 47). For example, substantive processing is not used in retrieving a judgment of a target for whom a prior opinion or stereotype exists, but it is used in the formulation of a completely novel judgment, in which target information needs to be compared and integrated with the judge's knowledge and beliefs. More complex, atypical tasks or targets involve higher levels of substantive processing. More generally, tasks that require handling a larger amount of information at once or that need a more extensive search in long-term memory involve higher levels of substantive processing than do tasks that require handling less information or performing a narrower memory search. Tasks that involve a higher degree of substantive processing are also more sensitive to the effects of mood (Bower \& Forgas, 2001; Fiedler, 2001; Forgas, 1995). ${ }^{1}$

This conceptual framework offers a useful framing for the potential effects of mood on the comprehension of valenced text. Specifically, mood should have a greater influence on readers' experience of valenced narrative endings when a higher degree of substantive processing is employed. To test this hypothesis, we used two tasks that required readers to engage in lesser or greater amounts of substantive processing. These tasks were moment-by- moment integration and reflection. The measures collected for each of them were reading latencies and judgments, respectively.

Theories of narrative processing have typically considered reading latencies and judgments to index the same cognitive process. For example, in prior work in our lab (e.g., Rapp \& Gerrig, 2002, 2006), the patterns of data converge for moment-by-moment reading and reflective judgments. Still, such a convergence between the measures is not necessarily the rule. For example, it is well known that readers understand characters' actions in reference to the most local goal (Magliano \& Radvansky, 2001; Suh \& Trabasso, 1993). However, this generalization holds for moment-by-moment integration processes, but not necessarily for reflective processes. Readers understand characters' actions in reference to a recent, local goal during moment-by-moment reading, and in reference to a more urgent, distal goal when formulating judgments (Egidi \& Gerrig, 2006). Recent neuroimaging studies (e.g., Hasson, Nusbaum, \& Small, 2006) also support the dissociation between natural comprehension and reflective processing of language, since these studies have shown that the two rely - at least partially - on different functional networks. During sentence comprehension, frontal and left temporal regions show increased activation when participants judge the sensibility of sentences as compared with when they listen to the sentences for comprehension (Hasson et al., 2006).

On the basis of this dissociation, we suggest that integration and reflection engage different levels of substantive processing because they differ in the amount of information they require readers to handle at once and in the type of elaboration applied to that information. Reading often prompts integration with a large amount of information, especially when access to the distal portion of the text is necessary (Albrecht \& Myers, 1995, 1998; Gerrig \& O'Brien, 2005), but such access does not always take place (Egidi \& Gerrig, 2006; McKoon \& Ratcliff, 1992; O’Brien \& Myers, 1999). In contrast, the judgment task that we used involves the formulation of a novel judgment (that presupposes successful integration) and by definition requires evaluating the ending of a story with respect to a large amount of information - that is, the entire story.

How, then, should ending valence and mood affect these two processes? Consider this brief story from our experiments:

Danny and Claire had rehearsed their dance several times. During the competition, Claire almost slipped once. They got right back on track and kept going. Afterward, they asked their coach how she thought they did. "We'll have to see if the judges think you made a mistake," she said. They waited for the judges to announce the scores.

To assess integration processes, we asked participants to read the narratives for comprehension and measured reading time on the ending sentence, "The judges gave Danny and Claire low marks" (Experiment 1). To assess reflective processes, we asked participants to judge how surprising they found the positive or negative end- 
ing (Experiment 2). Because negative information tends to capture attention, in Experiment 1 we expected that negative endings would constrain integration processes during reading. However, we expected people's moods to have a limited influence on moment-by-moment reading comprehension, because integration requires a degree of substantive processing that may not be sufficient for mood to have a strong impact.

Depending on the task and the cognitive processes mediating it, negative information has been associated with either increased or decreased task latencies. For example, in visual searches, negative stimuli are detected faster (see, e.g., Hansen \& Hansen, 1988) because the attentioncapturing quality of negative information makes negative stimuli easier to detect. However, in tasks such as Stroop or lexical decision, negative words are associated with longer latencies, because attention is disengaged more slowly from negative words (e.g., Estes \& Adelman, 2008; Pratto \& John, 1991). As a consequence, responses to other aspects of the stimulus, such as its color or lexical status, become more difficult. In the case of momentby-moment integration during reading, we expected that negative information would lead to longer latencies. We hypothesized that negative information would be devoted more attention and therefore that it would be either processed more carefully or integrated with greater difficulty.

By contrast, in Experiment 2, we expected the judgment task to engage sufficient substantive processing to yield mood effects. Thus, we expected to see a mood congruence effect in which participants judged endings that were inconsistent with their moods as being more surprising.

\section{EXPERIMENT 1}

The goal of Experiment 1 was to investigate the possibility of negativity bias and mood congruence in readers' integrations of story outcomes. We predicted that participants would take longer to read endings with negative valence (as compared with those with positive valence). Because moment-by-moment reading involves a moderate degree of substantive processing, we did not expect to see a strong impact of mood on this bias.

Experiment 1 had three phases. In the baseline test phase, participants read brief stories with positive or negative endings and we measured their reading times for those endings. This allowed us to assess the baseline impact of ending valence on reading time independent of readers' moods. The second phase was the mood induction phase. Participants read a separate group of stories that we intended would induce either a happy or a sad mood. In the postinduction test phase, participants read additional stories with positive or negative endings and, once again, we measured their reading times. This allowed us to compare how participants read the endings when they were feeling in a positive or negative mood with how they had read these endings when they were feeling in a more neutral mood. Participants read half of the stories in the baseline test phase and the other half in the postinduction test phase.
Table 1

Two Examples of Mood-Inducing Stories

\section{Story Inducing a Positive Mood}

The Pill That Makes You Fly

A man went into a bar in a high rise. He saw another man take a pill, take a drink, walk to the window and jump out. He flew around for a minute and zipped back into the bar. As the amazed newcomer watched, the man repeated this twice more. Finally the man asked if he could have a pill. The flier said it was his last one. The man offered five hundred dollars to no avail, so he made a final offer of a thousand dollars. The man said that it was all he had on him. The flier reluctantly gave in, took the cash, surrendered the pill, and turned back to the bar. The man took the pill, took a drink, went to the window, and jumped out only to fall to his death. The bartender walked over to the flier at the bar and, wiping a glass, said, "You sure are mean when you're drunk, Superman."

\section{Darfur}

\section{Story Inducing a Negative Mood}

When Alawi reached Kounoungo, the camp was already overcrowded. The militia had burned down Alawi's village and he had to run away. He had hoped to find rest and some food in the camp. But when he saw Kounoungo he understood that his hopes were in vain. Although less than six months old, the camp already sheltered too many refugees. Alawi had to beg for food in the nearby villages, because there was none left in the camp. Tortured by stomach cramps, he had to wait in line for hours to get a half gallon of water. Diseases had started to spread and the relief workers didn't know what to do. Some of them had started to leave the camp. Alawi, and many others, understood that the relief workers were giving up.

\section{Method}

Participants. Ninety-five undergraduates from Stony Brook University participated in this experiment for research credit (47 in the positive mood group and 48 in the negative mood group). All were native speakers of English.

Materials. We used 40 stories to induce moods and 20 neutral stories to test the effect of mood and ending valence on comprehension. The mood-inducing stories consisted of jokes and sad stories of various lengths. Table 1 provides examples. We used a norming procedure to select stories that would be effective in making participants feel either cheerful or sad. We created a questionnaire that contained 34 funny stories and $22 \mathrm{sad}$ stories in random order. Twenty-one native English-speaking undergraduates read these stories. For each story, they indicated how it made them feel on two scales. The first scale ranged from 1 (happy) to 7 (sad) and the second one from 1 (cheerful) to 7 (gloomy). Because the two scales were highly correlated $(r=.99)$, we combined them to create a single measure of affective response. On the basis of this norming, we selected 25 positive $(M=2.50)$ and 15 negative $(M=5.99)$ stories. This difference was statistically reliable in both participant $\left(t_{1}\right)$ and item $\left(t_{2}\right)$ analyses $\left[t_{1}(20)=-15.02\right.$, $\left.p<.001 ; t_{2}(38)=45.53, p<.001\right]$. The two groups of stories also differed in their distance from the extremes of the scale. Negative stories were closer to the negative extreme (7) of the scale than the positive stories were to the positive extreme ( 1 ) of the scale $\left[t_{1}(20)=2.87, p<\right.$ $\left..05 ; t_{2}(38)=6.35, p<.001\right]$. This difference might indicate that negative stories generated a more extreme affective response. However, both groups of stories were significantly distant from the midpoint of the scale [positive stories, $t_{1}(20)=-8.88, p<.001 ; t_{2}(24)=35.81$, $p<.001 ;$ negative stories, $t_{1}(20)=17.39, p<.001 ; t_{2}(14)=-28.28$, $p<.001]$.

Finally, because we intended to induce different moods in different groups of participants, the stories we chose were also comparable in total number of syllables ( positive stories $=4,136$; negative stories $=4,227$ ). For the mood induction phase of Experiment 1, we distributed the stories in two questionnaires, one of which contained the happy stories and the other one the sad stories.

The test stories that appeared before and after the mood induction phase were five to eight sentences long. The first few sentences introduced a scenario that was followed by one sentence stating ei- 
ther a positive or a negative ending. Each story had two versions: one with a positive ending and one with a negative ending. We constructed the stories so that each ending would be a natural conclusion and so that readers would not expect either one of them (on the basis of a norming study, as is detailed below). In addition, the bodies of the stories were emotionally neutral and did not contain affectively valenced language (i.e., words such as sad, happy, worried, elated). For each story, we minimized the lexical and semantic overlap between the endings and the rest of the story. In those cases in which some overlap was inevitable, we ensured that both positive and negative endings shared the overlap. All ending sentences were between 9 and 11 syllables long and shared similar syntactic structure. We took these precautions so that it would be possible to compare the reading times of these sentences. The stories ended with a final sentence that was neutral with respect to the prior context. Table 2 provides sample stories.

To ensure that participants would not find either ending more likely than the other, we normed the test stories. We wrote 26 candidate stories and distributed them into two booklets. Thirty native English-speaking undergraduates read each story without its ending. They then rated how surprising they found either the positive or negative ending of the story on a scale from 1 (not surprising at all) to 9 (extremely surprising). To ensure that participants would use the entire range of the scale, we added 12 filler stories, half of which were followed by obvious endings and the other half by unexpected endings. The distribution of positive and negative endings was counterbalanced and equated across questionnaires, and the order of the stories was randomized for each participant. After this norming, we chose 20 stories so that the mean surprise ratings for the positive endings $(M=3.63)$ were quite similar to those for the negative endings $(M=3.52)\left[t_{1}(29)=-0.650, p=.521\right.$; $\left.t_{2}(19)=0.631, p=.535\right]$. For most of these stories, the positive and negative endings had the same number of syllables and a few differed by one syllable only. Overall, the average number of syllables for positive and negative endings was identical $(M=10.2)$. We used 10 of these stories in the baseline test phase and 10 in the postinduction test phase. Half of the stories used in each phase had positive endings and the other half had negative endings. We used a Latin square to distribute the stories to eight different lists in a counterbalanced fashion.

Additionally, we constructed five stories that were similar to the test stories in length and structure to be used as practice stories. For

\section{Table 2}

\section{Two Examples of Test Stories}

Danny and Claire had rehearsed their dance several times. During the competition, Claire almost slipped once. They got right back on track and kept going. Afterward, they asked their coach how she thought they did. "We'll have to see if the judges think you made a mistake," she said. They waited for the judges to announce the scores.

Positive ending: The judges gave Danny and Claire high marks.

Negative ending: The judges gave Danny and Claire low marks.

Final sentence used only in Experiment 1: Then they announced the scores of the next couple.

Comprehension sentence: Danny and Claire danced together.

Ed and Frank were browsing the Internet to buy a new computer. Ten days earlier they had found sales on a couple of websites. One offer in particular seemed to match their needs and their budget, but they could not remember how long the offer would be valid. They went on the website and looked again.

Positive ending: The online deal was still available.

Negative ending: The online deal had already expired.

Final sentence used only in Experiment 1: It was a discount on a new model.

Comprehension sentence: Ed and Frank weren't sure whether the deal they wanted was still available. each of the practice and experimental stories, we wrote comprehension questions that we used to ascertain that participants would read carefully. For the test stories, half of the correct answers to the questions were "yes," and the other half were "no," in a counterbalanced fashion.

Design. Participants read stories with positive or negative endings after being induced into a positive or negative mood. Thus, the design consisted of a between-participants and within-items variable, mood valence (positive, negative), and a within-participants and within-items variable, ending valence (positive, negative).

Procedure. The experiment had three phases: a baseline test phase, a mood induction phase, and a postinduction test phase. The two test phases were conducted on a computer that recorded reading times and responses to comprehension questions. The mood induction phase was conducted on paper. Our aim was to diversify the procedures so that participants would not see a connection between the mood induction phase and the test phases. As a cover story, we told participants that they would complete two separate studies.

In the baseline test phase, participants read a set of stories on a computer screen. Before each story the sentence "Press NEXT for the next story" appeared on the screen and participants hit a key marked NEXT to start. The stories appeared in a different random order for each participant, line by line, in the center of the screen and in standard upper- and lowercase type. Participants pressed a key to advance the lines and continue reading. At the end of each story, participants heard a warning sound from the computer and saw the prompt, "Is the following statement true?" followed by a comprehension sentence. If they thought that the sentence was true, they pressed the key marked as YES. If they thought that it was not true, they pressed the key marked as NO. After giving their response, they received feedback (i.e., CORRECT or INCORRECT). Participants were instructed to read everything carefully and to respond as quickly as they could without making mistakes.

Participants began the experiment by reading the five practice stories. At the end of the practice, the software notified them that the experimental session was about to begin. Then they proceeded to read the first block of stories, which consisted of the first test phase. At the end of this block, when participants hit the key to begin a new story, a fake error message appeared on the screen. When they notified the experimenter, she apologized and suggested that they complete the other study - which consisted of reading the mood induction stories - while she figured out the problem. The experimenter told them that once they finished the other study, they could return to the computer and continue from where they had been interrupted. We intended this ruse to allow us to induce moods in participants without them suspecting that the mood-inducing stories were related to the test stories. In fact, directing people's attention to their affective states has been shown to give rise to demand effects and to trigger strategic processing that reduces the effects of mood (Berkowitz, Jaffee, Jo, \& Troccoli, 2000; M. Martin, 1990).

In the mood induction phase, participants moved to an adjacent room and completed one of the mood-inducing questionnaires. To ensure that participants would read carefully, we asked them after each story to rate how interesting they found the story on a scale from 1 (boring) to 9 (interesting). We told participants that this was a norming study and briefly explained the general procedure and function of a norming. We instructed participants to read the stories carefully and to respond by expressing their opinions.

The order of the stories was randomized for each participant. However, the last page of each questionnaire was the same for all participants and contained four questions. Three were filler questions about the stories, and one asked participants to rate how they felt at that time on a scale from 1 (happy) to 9 ( $\mathrm{sad}$ ). The purpose of this question was to assess whether the mood manipulation was successful. We introduced the filler questions to hide the real purpose of the questionnaires and to avoid experimental demand effects on mood ratings. Finally, to ensure that the experimenter would remain blind to the mood manipulation, we stored and distributed the 
questionnaires text-side down so that the experimenter could not see which group of stories they contained and would not be aware of which mood they would induce.

When participants had completed this phase, they were given a fake debriefing about the purpose of the norming study they had just completed. Then they returned to the computer room to complete the interrupted study. This started the postinduction test phase. Participants were briefly reminded of the instructions and completed the reading of the test stories. Finally, participants completed a fourquestion survey that again contained three fillers and a question asking participants to rate how they felt on a scale from 1 (happy) to $9(\mathrm{sad})$. The aim of this question was to assess whether the mood induction was effective throughout the experiment. Immediately before the debriefing, participants were asked what they thought the study was testing. We intended for this brief interview to assess whether participants had had any suspicion about the experimental manipulation of mood. None of them reported any suspicion.

\section{Results and Discussion}

Mood induction. At both stages of the experiment, participants who had read happy stories rated themselves as being in a better mood than did participants who had read sad stories. Following the mood induction, mean ratings were 2.62 (smaller numbers indicated greater happiness) for the group who had read happy stories and 7.02 for the group who had read sad stories $[t(93)=-16.78$, $p<.001]$. At the end of the study, participants gradually returned to more neutral moods, but still rated themselves differently: The average ratings were 3.55 for participants who had read the happy stories and 4.19 for participants who had read the sad stories $[t(93)=-2.02, p<.05]$.

Reading latencies. To measure how participants integrated positive and negative endings during reading, we collected their reading latencies for the ending sentences. We started the analysis by removing errors and responses that were more than 3 standard deviations above and below each condition's mean. This procedure resulted in a loss of $1.94 \%$ of the data. Table 3 shows the pattern of results.

We had expected that a negativity bias would emerge in the reading latencies and that mood would not exert a great influence on this bias. Thus, we expected that negative endings would take longer to process than would positive endings in both test phases. In fact, participants read negative endings $152 \mathrm{msec}$ slower than positive endings across both test phases. This result was confirmed by analyses with participants $\left(F_{1}\right)$ and items $\left(F_{2}\right)$ as random variables $\left[F_{1}(1,79)=44.07, M S_{\mathrm{e}}=44,992.85, p<.001\right.$; $\left.F_{2}(1,16)=7.51, M S_{\mathrm{e}}=119,642.46, p<.05\right]$.

Recall that the baseline test phase occurred before the mood induction phase. Therefore, the pattern of reading latencies of this phase reflects how participants processed positive and negative endings in a relatively neutral mood. In the postinduction test phase, however, participants had been induced into a positive or a negative mood. As a consequence, the reading latencies of this phase reflect how mood modulated participants' readings of positive and negative endings. As is seen in Table 3 , mood did not have a strong impact; there was no interaction of negativity bias with mood (interaction $F_{\mathrm{S}}<1$ ). Finally, in the postinduction test phase, participants read the endings faster than they did in the first test phase $\left[F_{1}(1,79)=\right.$ $15.62, M S_{\mathrm{e}}=65,822.23, p<.001 ; F_{2}(1,16)=40.85$, $\left.M S_{\mathrm{e}}=10,248.88, p<.001\right]$. This difference most likely reflects practice effects in performing the experimental task. No other effect was reliable in both participant and item analyses.

In conclusion, Experiment 1 supported the prediction that during moment-by-moment reading, participants would succumb to a bias to attend at greater length to information with a negative valence. We did not find mood congruence. However, we expected that the relative impact of ending valence and mood would shift when readers engaged in evaluations of positive and negative endings. We investigated these circumstances in Experiment 2.

\section{EXPERIMENT 2}

The goal of Experiment 2 was to investigate the impact of mood on participants' judgments of story endings. We predicted that participants' judgments would be influenced by mood valence because this kind of judgment requires a high degree of substantive processing. In particular, we expected that participants would find endings that were congruent with their moods to be more likely, thus showing mood congruence. Experiment 2 had two phases. The first consisted in the mood induction. As in Experiment 1, we induced participants to experience positive or negative moods by reading happy or sad stories in a mock norming study. During the second phase - the test phase - participants read the test stories on paper and judged how surprising they found either the positive or negative endings. We later compared those ratings with those provided by a control group whose mood had not been experimentally manipulated. ${ }^{2}$

In Experiment 2, we asked participants to rate their moods only at the end of the experiment. We were unable to use a ruse like the fake error used in Experiment 1, but we still wanted to minimize the chance that participants

Table 3

Results of Experiment 1: Mean Reading Latencies and

Standard Deviations (in Milliseconds) for

Story Endings As a Function of Mood

\begin{tabular}{|c|c|c|c|c|c|c|c|c|c|c|}
\hline \multirow[b]{3}{*}{ Mood } & \multicolumn{5}{|c|}{ Baseline Test Phase } & \multicolumn{5}{|c|}{ Postinduction Test Phase } \\
\hline & \multicolumn{2}{|c|}{$\begin{array}{l}\text { Positive } \\
\text { Ending }\end{array}$} & \multicolumn{2}{|c|}{$\begin{array}{c}\text { Negative } \\
\text { Ending }\end{array}$} & \multirow[b]{2}{*}{$M$} & \multicolumn{2}{|c|}{$\begin{array}{l}\text { Positive } \\
\text { Ending }\end{array}$} & \multicolumn{2}{|c|}{$\begin{array}{l}\text { Negative } \\
\text { Ending }\end{array}$} & \multirow[b]{2}{*}{$M$} \\
\hline & $M$ & $S D$ & $M$ & $S D$ & & $M$ & $S D$ & $M$ & $S D$ & \\
\hline Positive & 1,908 & 483 & 2,019 & 456 & 1,963 & 1,800 & 475 & 1,964 & 480 & 1,882 \\
\hline Negative & 2,060 & 526 & 2,205 & 618 & 2,133 & 1,916 & 515 & 2,101 & 563 & 2,008 \\
\hline$M$ & \multicolumn{2}{|c|}{1,984} & \multicolumn{2}{|c|}{2,113} & & \multicolumn{2}{|c|}{1,859} & \multicolumn{2}{|c|}{2,033} & \\
\hline
\end{tabular}


would understand the purpose of the experiment. For this reason, it seemed prudent to assess mood just a single time at the experiment's conclusion (as in, e.g., Forgas, 1998a, 1998c). Given that we used the same mood-inducing method and materials as in Experiment 1, we believed that the manipulation would work just as well.

\section{Method}

Participants. Sixty native English speakers who were undergraduate students from Stony Brook University participated in this experiment for partial fulfillment of course requirements. In 30 participants, a positive mood was induced, and in the other 30 , a negative mood.

Materials. We used the same mood induction and test stories as in Experiment 1. However, we did not use the final sentences of the test stories.

Design. Participants rated their surprise in reading positive or negative endings in the context of a positive, negative, or neutral mood induction. Thus, the design consisted of a between-participants and within-items variable, mood valence (positive, negative, neutral) and a within-participants and within-items variable, ending valence (positive, negative).

Procedure. Both the mood induction and postinduction test phases were conducted with paper and pencil. To diversify the two phases enough so that participants would not see a connection, we told them that they would be completing two separate studies. These were presented as two norming studies for two different future experiments. After we explained the general procedure and function of a norming study, we gave participants the same mood-inducing stories as in Experiment 1. Care was taken to ensure that the experimenter would not influence participants by storing and distributing the questionnaires text-side down, as in Experiment 1.

After participants had filled out the mood induction questionnaire, we gave them the second booklet containing the test stories. Participants read each story and then rated how surprising they found the ending on a scale from 1 (not surprising at all) to 9 (extremely surprising). Note that this task was quite different from that in which participants engaged while reading the mood-inducing stories. Here, participants evaluated how surprised they were by the endings with respect to the stories to which they belonged. In the mood induction questionnaire, they gave an overall judgment about how interesting they found each story in its entirety.

After participants completed this phase, we asked for their opinions about the purpose of the two future studies for which they had just read stories. We conducted this brief interview to assess whether participants had had any suspicions about the real purpose of the experiment. Only 1 participant had. The pattern of results was the same regardless of whether his data were included in the analysis. Therefore, we report data from the total number of participants.

Finally, before the debriefing, participants completed a survey of 10 questions allegedly about the experiments they had just completed. The survey actually assessed the success of the mood induction. The first question asked participants how they felt right after they had read the mood-inducing stories; the second one asked participants how they felt at the end of the experiment. Participants rated their mood on a scale ranging from 1 (happy) to 9 ( sad). The other questions were fillers that we introduced to hide the real purpose of the survey and thus minimize demand effects on the mood ratings.

\section{Results and Discussion}

Mood induction. Participants who read happy stories rated themselves as being in a better mood after the mood induction, but this difference did not endure to the end of the experiment. The mean ratings to the question assessing how participants felt after reading the mood-inducing stories were 2.73 and 5.97 for participants in the positive and negative mood conditions, respectively $[t(58)=$
$-8.34, p<.001]$. However, participants' responses to the question that assessed their mood after completing both stages of the experiment were 4.77 and 4.63 for participants who had read the happy and the sad stories, respectively $(t<1)$.

Surprise ratings. To measure how participants evaluated story endings as a function of their mood, we collected participants' ratings on how surprising they found the endings. We expected that mood would influence these judgments in a mood-congruent fashion, so that participants would judge as more surprising endings mismatching their mood in valence. As Table 4 shows, participants in the positive mood condition rated positive endings as less surprising than did participants in the negative mood condition. They also judged negative endings as being more surprising than did participants in the negative mood condition. This resulted in a reliable interaction between mood and ending valence $\left[F_{1}(1,56)=6.68, M S_{\mathrm{e}}=.371\right.$, $\left.p<.05 ; F_{2}(1,18)=25.44, M S_{\mathrm{e}}=.066, p<.001\right]$. Thus, participants' levels of surprise for positive and negative endings varied as a function of their mood. No other effect was reliable in the participant and item analyses.

Additionally, we wanted to determine whether both moods created a shift in surprise judgments with respect to a baseline neutral mood. Therefore, we conducted an analysis that included data from a group of participants in which mood had not been experimentally manipulated. These were the 30 participants who took part in the norming of the stories and who, with the same procedure used in this experiment, had rated these positive and negative endings as being equally surprising. Although we did not measure the moods of these participants, we assumed that, on average, their moods were neutral (e.g., as in Forgas, 1998b). For this analysis, we subtracted the ratings of this neutral norming group from those given by the participants in positive and negative moods. As is shown in Table 4, participants in the positive mood condition found negative endings more surprising than did participants in neutral moods, and they found positive endings equally surprising (this difference was, in fact, 0). Conversely, participants in the negative mood condition found positive endings more surprising than did participants in neutral moods, and they found negative endings equally surprising (this difference was also 0 ). This pattern resulted in a reliable interaction of these difference scores $\left[F_{1}(1,56)=\right.$ $6.68, M S_{\mathrm{e}}=.371, p<.05 ; F_{2}(1,18)=25.44, M S_{\mathrm{e}}=.066$, $p<.001]$, indicating that surprise judgments for positive

Table 4

Results of Experiment 2: Mean Ratings of Story Endings As a Function of Mood, Standard Deviations, and Mean Rating Difference Between Participants in the Two Mood Groups and a Group of Participants Whose Mood Was Not Manipulated

\begin{tabular}{|c|c|c|c|c|c|c|}
\hline \multirow[b]{4}{*}{ Mood } & \multicolumn{4}{|c|}{ Mean Ratings } & \multirow{2}{*}{\multicolumn{2}{|c|}{$\begin{array}{c}\text { Mean Ratings } \\
\text { Difference }\end{array}$}} \\
\hline & \multirow{2}{*}{\multicolumn{2}{|c|}{$\begin{array}{l}\text { Positive } \\
\text { Ending }\end{array}$}} & \multirow{2}{*}{\multicolumn{2}{|c|}{$\begin{array}{c}\text { Negative } \\
\text { Ending }\end{array}$}} & & \\
\hline & & & & & Positive & Negative \\
\hline & $M$ & $S D$ & $M$ & $S D$ & Ending & Ending \\
\hline Positive & 3.60 & 1.03 & 3.83 & 1.07 & -0.03 & 0.31 \\
\hline Negative & 3.84 & 1.14 & 3.50 & 0.94 & 0.21 & -0.02 \\
\hline
\end{tabular}


and negative endings were mediated by mood. Although the predicted interaction was reliable, post hoc contrasts did not reveal significant differences between the pairs of means within each mood. However, the interaction pattern itself shows that surprise ratings for positive and negative endings were mediated by mood in a way that corresponds to mood congruence.

\section{GENERAL DISCUSSION}

Our experiments investigated how the valence of story endings and readers' moods influenced readers' experiences of a narrative. Our aim was to provide a broad perspective on reading processes, so we considered how mood and valence interact when readers are engaged in either moment-by-moment integration or deliberate reflection on the materials. These processes represent typical activities that occur when readers process narratives. Thus, our experiments provide a comprehensive picture of the reading process, from the emergence of moods generated by the text itself to the impact of such moods on further moment-by-moment reading and subsequent reflective processes.

We hypothesized that during moment-by-moment reading, negative endings would attract greater attention and result in slower latencies. We also hypothesized that mood would be more likely to have an impact when a higher degree of substantive processing was required. Thus, we expected that mood congruence would be more likely to emerge in readers' judgments of the stories' endings than during moment-by-moment integration. The experiments corroborated these predictions.

Our examination provides an initial step on a topic relatively unexplored by language comprehension theories, since this literature has largely overlooked the effect of mood or ending valence on comprehension. Only a few studies have focused on affective responses generated by narratives, and even these studies have limited their scopes to transient states, such as preferences and desires (Allbritton \& Gerrig, 1991; Rapp \& Gerrig, 2002, 2006). For this reason, the theoretical basis for our predictions was largely drawn from studies that have examined negativity bias and mood congruence effects in other domains of cognition.

The present results show that the effect of mood differs in an important way from the effect of transient emotional states on language comprehension. Transient states (e.g., wishing for a specific plot outcome; Rapp \& Gerrig, $2002,2006)$ have been shown to affect both reading times and participants' judgments about what is likely to happen next in a story. In contrast, in the present experiments the effects of mood appeared to be more subtle and held only when participants were asked to reflect on the story in its entirety. One reason for the dissociation between transient states and mood effects might be that in prior studies on narrative processing, transient wishes and preferences for one specific plot outcome were related to the narrative in a way that moods are not. By including semantic content that can match or mismatch the actual outcome, read- ers' wishes for a specific story outcome bear directly on the integration process of a given outcome because they have direct relevance for the story. For example, in one story used by Rapp and Gerrig (2006), the text created a preference for a runner to lose a race by noting that she had taken steroids earlier. The content of this wish (e.g., "I hope she does not win!") was directly relevant to the actual outcome that the character won or lost the marathon. To date, the evidence on the extent of the similarity between readers' wishes and moods is too sparse for us to be able to go beyond this speculation. We expect that, as research develops, the circumstances in which the influence of transient states and mood diverge or converge will become clearer.

In Experiment 1, participants read negative endings more slowly than they did positive endings. We suggested that due to the attention-grabbing quality of negative information, negative endings are devoted more careful processing or are more difficult to integrate. It is possible, however, that increased latencies for negative endings may reflect readers' updating of characters' emotional status (as in Komeda \& Kusumi, 2006). Readers may tend to attribute a mildly positive emotional state to the story characters as a default and therefore need to update their model of characters' emotional status when the character experiences a negative event. Although readers can form representations of characters' emotional states (see, e.g., Gernsbacher, Goldsmith, \& Robertson, 1992), updating effects of the type we outlined above have been documented only with stories whose main theme was the emotions experienced by the character (Komeda \& Kusumi, 2006). Note that we constructed our stories to be as emotionally neutral as possible; they never mentioned characters' emotional states. In addition, as was indicated by the results of the norming, our stories prepared readers equally well for positive and negative endings.

In Experiment 2, participants judged as more surprising those endings that mismatched their moods. We interpreted this pattern to be an instantiation of a mood congruence effect. An alternative explanation for these results is that once participants were induced into a given mood (by reading valenced materials), they later came to expect that the following materials would be of the same valence. On the basis of this explanation, surprise ratings reflected an expectancy mechanism rather than a genuine influence of mood. However, if the strategic expectancy mechanism were put into place because participants had read the mood-inducing stories, a similar expectancy effect should have held in Experiment 1 as well. Additionally, our test stories were very different in form from the mood-inducing stories. We also presented the mood induction and the test phase as two separate studies, to minimize the possibility that participants would expect the second part of the experiment to be commensurable with the first.

In summary, the present results allow us to outline a model of how mood and text valence can affect narrative comprehension. The valence of the stimulus and the valence of people's moods weigh differently on moment-by- 
moment comprehension and subsequent reflection. It is possible that a replication with a different mood induction technique or a larger sample would show an emergence of mood effects during moment-by-moment reading. However, our experiments suggest that reflective processes are more sensitive to readers' moods than are integration processes.

The present findings also indicate that theories of text processing can benefit from considering the effects that readers' moods have on text comprehension. Although the focus of such theories is prominently on the processing of information that readers encounter in the text, the present research demonstrates that the internal emotional state of the reader influences some of the processes involved in narrative comprehension.

\section{AUTHOR NOTE}

We thank Suparna Rajaram, Antonio Freitas, Milton Lodge, and Howard Nusbaum for their helpful comments on this research. We also thank Alayna Friedline for her assistance in stimulus preparation and data collection. The present research was based on work supported by National Science Foundation Grant 0325188. The preparation of this manuscript was supported by the John Templeton Foundation. Address correspondence to G. Egidi, Center for Cognitive and Social Neuroscience, Department of Psychology, University of Chicago, 5848 S. University Avenue, Chicago, IL 60637 (e-mail: g.egidi@gmail.com).

\section{REFERENCES}

Albrecht, J. E., \& Myers, J. L. (1995). Role of context in accessing distant information during reading. Journal of Experimental Psychology: Learning, Memory, \& Cognition, 21, 1459-1468. doi:10.1037/0278 $-7393.21 .6 .1459$

Albrecht, J. E., \& Myers, J. L. (1998). Accessing distant text information during reading: Effects of contextual cues. Discourse Processes, 26, 87-107.

Allbritton, D. W., \& Gerrig, R. J. (1991). Participatory responses in text understanding. Journal of Memory \& Language, 30, 603-626. doi:10.1016/0749-596X(91)90028-I

Baumeister, R. F., Bratslavsky, E., Finkenauer, C., \& Vohs, K. D. (2001). Bad is stronger than good. Review of General Psychology, 5, 323-370. doi:10.1037/1089-2680.5.4.323

Berkowitz, L., Jaffee, S., Jo, E., \& Troccoli, B. T. (2000). On the correction of feeling-induced judgmental biases. In J. P. Forgas (Ed.), Feeling and thinking: The role of affect in social cognition (pp. 131152). New York: Cambridge University Press.

Bower, G. H. (1981). Mood and memory. American Psychologist, 36, 129-148. doi:10.1037/0003-066X.36.2.129

Bower, G. H., \& Forgas, J. P. (2000). Affect, memory, and social cognition. In E. Eich \& J. F. Kihlstrom (Eds.), Cognition and emotion (pp. 87-168). New York: Oxford University Press.

Bower, G. H., \& Forgas, J. P. (2001). Mood and social memory. In J. Forgas (Ed.), Handbook of affect and social cognition (pp. 95-120). Mahwah, NJ: Erlbaum.

Bower, G. H., Gilligan, S. G., \& Monteiro, K. P. (1981). Selectivity of learning caused by affective states. Journal of Experimental Psychology: General, 110, 451-473. doi:10.1037/0096-3445.110.4.451

Cacioppo, J. T., Gardner, W. L., \& Berntson, G. G. (1997). Beyond bipolar conceptualizations and measures: The case of attitudes and evaluative space. Personality \& Social Psychology Review, 1, 3-25. doi:10.1207/s15327957pspr0101_2

Disksterhuis, A., \& AarTs, H. (2003). On wildebeests and humans: The preferential detection of negative stimuli. Psychological Science, 14, 14-18. doi:10.1111/1467-9280.t01-1-01412

EGIDI, G., \& GERRIG, R. J. (2006). Readers' experiences of characters' goals and actions. Journal of Experimental Psychology: Learning, Memory, \& Cognition, 32, 1322-1329. doi:10.1037/0278-7393.32.6.1322

Estes, Z., \& Adelman, J. S. (2008). Automatic vigilance for negative words in lexical decision and naming: Comment on Larsen, Mercer, and Balota (2006). Emotion, 8, 441-444. doi:10.1037/1528-3542.8.4.441

FiEDLER, K. (1991). On the task, the measures and the mood in research on affect and social cognition. In J. P. Forgas (Ed.), Emotion and social judgments (pp. 83-104). Oxford: Pergamon.

FIEDLER, K. (2001). Affective states trigger processes of assimilation and accommodation. In L. L. Martin \& G. L. Clore (Eds.), Theories of mood and cognition: A user's guidebook (pp. 85-98). Mahwah, NJ: Erlbaum.

ForGaS, J. P. (1992). On mood and peculiar people: Affect and person typicality in impression formation. Journal of Personality \& Social Psychology, 62, 863-875. doi:10.1037/0022-3514.62.5.863

ForGas, J. P. (1995). Mood and judgment: The affect infusion model (AIM). Psychological Bulletin, 117, 39-66. doi:10.1037/0033-2909 .117 .1 .39

ForGas, J. P. (1998a). Asking nicely? The effects of mood on responding to more or less polite requests. Personality \& Social Psychology Bulletin, 24, 173. doi:10.1177/0146167298242006

FoRGAS, J. P. (1998b). On being happy and mistaken: Mood effects on the fundamental attribution error. Journal of Personality \& Social Psychology, 75, 318-331. doi:10.1037/0022-3514.75.2.318

ForGaS, J. P. (1998c). On feeling good and getting your way: Mood effects on negotiator cognition and bargaining strategies. Journal of Personality \& Social Psychology, 74, 565-577. doi:10.1037/0022 $-3514.74 .3 .565$

Forgas, J. P., \& Bower, G. H. (1987). Mood effects on personperception judgments. Journal of Personality \& Social Psychology, 53, 53-60. doi:10.1037/0022-3514.53.1.53

Forgas, J. P., \& Fiedler, K. (1996). Us and them: Mood effects on intergroup discrimination. Journal of Personality \& Social Psychology, 70, 28-40. doi:10.1037/0022-3514.70.1.28

Forgas, J. P., Laham, S. M., \& Vargas, P. T. (2005). Mood effects on eyewitness memory: Affective influences on susceptibility to misinformation. Journal of Experimental Social Psychology, 41, 574-588. doi:10.1016/j.jesp.2004.11.005

Gernsbacher, M. A., Goldsmith, H. H., \& Robertson, R. R. W. (1992). Do readers mentally represent characters' emotional states? Cognition \& Emotion, 6, 89-111.

Gerrig, R. J., \& O'Brien, E. J. (2005). The scope of memorybased processing. Discourse Processes, 39, 225-242. doi:10.1207/ s15326950dp3902\&3_7

HANSEN, C. H., \& HANSEN, R. D. (1988). Finding the face in the crowd: An anger superiority effect. Journal of Personality \& Social Psychology, 54, 917-924. doi:10.1037/0022-3514.54.6.917

Hasson, U., Nusbaum, H. C., \& Small, S. L. (2006). Repetition suppression for spoken sentences and the effect of task demands. Journal of Cognitive Neuroscience, 18, 2013-2029. doi:10.1162/ jocn.2006.18.12.2013

HERR, P. M., KARDES, F. R., \& KiM, J. (1991). Effects of word-of-mouth and product-attribute information on persuasion: An accessibilitydiagnosticity perspective. Journal of Consumer Research, 17, 454.

Ito, T. A., Larsen, J. T., Smith, N. K., \& CaCioppo, J. T. (1998). Negative information weighs more heavily on the brain: The negativity bias in evaluative categorizations. Journal of Personality \& Social Psychology, 75, 887-900. doi:10.1037/0022-3514.75.4.887

Komeda, H., \& Kusumi, T. (2006). The effect of a protagonist's emotional shift on situation model construction. Memory \& Cognition, 34, 1548-1556.

Magliano, J. P., \& Radvansky, G. A. (2001). Goal coordination in narrative comprehension. Psychonomic Bulletin \& Review, 8, 372-376.

Martin, L. L., \& Clore, G. L. (2001). Theories of mood and cognition: A user's guidebook. Hillsdale, NJ: Erlbaum.

Martin, M. (1990). On the induction of mood. Clinical Psychology Review, 10, 669-697. doi:10.1016/0272-7358(90)90075-L

McKenna, F. P., \& Sharma, D. (1995). Intrusive cognitions: An investigation of the emotional Stroop task. Journal of Experimental Psychology: Learning, Memory, \& Cognition, 21, 1595-1607. doi:10.1037/0278 $-7393.21 .6 .1595$

McKoon, G., \& Ratcliff, R. (1992). Inference during reading. Psychological Review, 99, 440-466. doi:10.1037/0033-295X.99.3.440

O'Brien, E. J., \& Myers, J. L. (1999). Text comprehension: A view from the bottom up. In S. R. Goldman, A. C. Graesser, \& P. van den 
Broek (Eds.), Narrative comprehension, causality, and coherence: Essays in honor of Tom Trabasso (pp. 35-53). Mahwah, NJ: Erlbaum.

Peeters, G., \& Czapinski, J. (1990). Positive-negative asymmetry in evaluations: The distinction between affective and informational negativity effects. European Review of Social Psychology, 1, 33-60.

Pratto, F., \& John, O. P. (1991). Automatic vigilance: The attentiongrabbing power of negative social information. Journal of Personality \& Social Psychology, 61, 380-391. doi:10.1037/0022-3514.61.3.380

RAPP, D. N., \& GERRIG, R. J. (2002). Readers' reality-driven and plotdriven analyses in narrative comprehension. Memory \& Cognition, 30, 779-788

RAPP, D. N., \& GERRIG, R. J. (2006). Predilections for narrative outcomes: The impact of story contexts and reader preferences. Journal of Memory \& Language, 54, 54-67.

Rozin, P., \& Royzman, E. B. (2001). Negativity bias, negativity dominance, and contagion. Personality \& Social Psychology Review, 5, 296-320. doi:10.1207/S15327957PSPR0504_2

Schwarz, N., \& Clore, G. L. (1983). Mood, misattribution, and judgments of well-being: Informative and directive functions of affective states. Journal of Personality \& Social Psychology, 45, 513-523. doi:10.1037/0022-3514.45.3.513

Smith, N. K., Cacioppo, J. T., Larsen, J. T., \& Chartrand, T. L. (2003). May I have your attention, please: Electrocortical responses to positive and negative stimuli. Neuropsychologia, 41, 171-183. doi: $10.1016 /$ S0028-3932(02)00147-1

Suh, S., \& Trabasso, T. (1993). Inferences during reading: Converging evidence from discourse analysis, talk-aloud protocols, and recognition priming. Journal of Memory \& Language, 32, 279-300. doi:10.1006/jmla.1993.1015

WATKINS, P. C. (2002). Implicit memory bias in depression. Cognition \& Emotion, 16, 381-402. doi:10.1080/02699930143000536
Watkins, P. C., Martin, C. K., \& Stern, L. D. (2000). Unconscious memory bias in depression: Perceptual and conceptual processes. Journal of Abnormal Psychology, 109, 282-289. doi:10.1037/0021 -843 X.109.2.282

Watkins, P. C., Mathews, A., Williamson, D. A., \& Fuller, R. D. (1992). Mood-congruent memory in depression: Emotional priming or elaboration? Journal of Abnormal Psychology, 101, 581-586. doi:10.1037/0021-843X.101.3.581

\section{NOTES}

1. Mood can also have an impact on judgments if used as a heuristic that triggers a response bias (see, e.g., Schwarz \& Clore, 1983). Also, negative mood leads to more careful processing of material (Forgas, Laham, \& Vargas, 2005) and to longer processing times than does positive mood (Forgas, 1992; Forgas \& Fiedler, 1996). We will not discuss these effects here because they are not relevant for the present research.

2 . We take participants' ratings of story endings to be a measure of their estimates of the predictability of those endings given prior context, which is an intuitive way to ask for a probability judgment-a task that involves reflective processing. We are not presently measuring surprise as a visceral or emotional response. To experience surprise, participants would have had to take the endings to be true in the context of the story and, as a consequence, experience that emotion. However, in the present study, participants read each story up to the ending and were told before they read the ending that they would have to evaluate it. Thus, the status of the ending was that of information to be evaluated.

(Manuscript received February 21, 2008; revision accepted for publication February 16, 2009.) 